\title{
Herbal Extracts Used in Dental Disorders
}

\author{
Bilge Şener* and Mehtap Kiliç \\ Faculty of Pharmacy, Department of Pharmacognosy, Turkey \\ *Corresponding author: Bilge Şener, Faculty of Pharmacy, Department of Pharmacognosy, Ankara, Turkey
}

\section{ARTICLE INFO}

Received: 幽 June 16, 2019

Published: 慧 June 25, 2019

Citation: Bilge Şener, Mehtap Kiliç. Herbal Extracts Used in Dental Disorders. Biomed J Sci \& Tech Res 19(1)-2019. BJSTR. MS.ID.003254.

Keywords: Herbal Extracts; Medicinal Plants; Dental Disorders

\begin{abstract}
Natural products have been recently investigated more thoroughly as promising agents for the prevention of oral diseases, especially plaque-related diseases such as dental caries. Oral diseases, a major health issue in the world, are economically affecting people of developed countries as $10 \%$ of the health expenditure is related to dental care. Different surveys showed that medicinal plant species used by the people for the traditional treatment of dental diseases are inadequately screened for their therapeutic/ preventive potential and phytochemical findings. In this review, some herbal extracts commonly used in dental disorders and their bioactivities are outlined.
\end{abstract}

\section{Introduction}

Medicinal plants play an important role for human health. Apart from traditional uses, many compounds isolated from them have useful medicinal properties for treating different diseases. They are promising source for identifing lead bioactive compounds. The significant contribution of medicinal plants to the drug industry, all over the world, was due to the increasing number of phytochemical and biological studies. Medicinal plants are an important source of developing new therapeutic agents. Plant species have long been regarded as possessing the principal ingredients used in widely disseminated ethnomedical practices. Plants used in traditional medicine present a natural and renewable source of secondary metabolites that can be used for producing new drugs and, therefore, the treatment of various human disorders. In addition, in developing countries the herbal medicines are providing to be phytochemicals isolated from plants used in traditional medicines, are considered to be safe and effective alternatives compared to synthetic chemicals. A wide variety of secondary metabolites in medicinal plants having in vitro different biological activities provide for novel drug compounds. Today, oral care products combined with medicinal plant extracts are gaining high interest due to their low toxicity and less side effects all over the world [1]. The main diseases of the teeth include plaque, caries and pyorrhea. Proper dental care is necessary for eliminating tooth decay and periodontal diseases. Prevention of dental caries is challenging, as the incidence of the disease is very high in general population and it occurs in economi cally deprived people who cannot afford the commercially available oral hygiene products. Even though caries is known to be an infectious disease for decades, very little effort has been done to use this information clinically. The numbers of drugs including cetylpyridinium chloride, amine fluorides, triclosan, and chlorhexidine are not only toxic, but also, they cause staining of teeth [2].

Herbal mouthwashes were statistically efficacious in controlling plaque and gingivitis with potent antimicrobial activity. Different from other commercially available chemicals, they not only alter the oral microbial environment but also play a role in developing the resistant strain. Hence, in order to prevent dental caries [3], it is time to focus our attention toward natural resources which have vast abilities to inhibit the growth of microbes that are responsible for caries. Herbal extracts have been used in dentistry for reducing inflammation, as antimicrobial plaque agents, for preventing release of histamine and as antiseptics, antioxidants, antimicrobials, antivirals and analgesics [4,5]. They also aid in healing and are effective in controlling microbial plaque in gingivitis and periodontitis and thereby improving immunity. This review will focus on the different herbal extracts used as common for prevention and treatment of the different oral diseases.

\section{Herbal Extracts and Their Bioactivities}

The most common medicinal plants used in dentistry for their different actions have been summarized. 


\section{Achillea millefolium L. (Asteraceae)}

Yarrow is used to treat hemorrhages, ulcers and to improve blood clotting, It is also used as mouth wash to promote healing of cuts in mouth due to surgery, teeth cleaning and braces [6].

\section{Aloe vera (L.) Burm. F. (Xanthorrhoeaceae)}

The gel extracted from the leaf parenchyma of Aloe vera contains a wide range of natural components that possess significant antiinflammatory, antioxidant, antifungal and angiogenic activities has been used for centuries for therapeutic purposes [7]. Aloe vera gel is effective in the treatment of various types of ulcers such as silver nanoparticles of $100 \mathrm{~nm}$ dimension and as antimicrobial effect of a broad spectrum of bacteria, in addition to anti-inflammatory, antifungal, and antiviral effects [8-11]. Their effects of topical application on oral ulcer healing were shown by using in irradiated mice. Their anti-inflammatory, enhanced re-epithelialization and fibroblast activation effects were also demonstrated [12,13].

\section{Camellia sinensis (L.) Kuntze (Theaceae)}

The leaves and leaf buds of Camellia sinensis are used to produce tea. According to fermentation process, green teas are richer in catechins than black tea. The unfermented green tea contains polyphenols epicatechin, epigallocatechin, epicatechin gallate and epigallocatechin gallate. Epigallocatechin-3-gallate is the major constituent of green tea. These secondary metabolites have a protective effect on dentin loss for inhibiting erosive attacks on susceptible hard-tooth substrates [14]. The plaqueinduced gingivitis occurred by by accumulation of microbial plaque containing more than 300 types of bacterial species as the most common form of periodontal disease $[15,16]$. Green tea mouthwash may be a safe and feasible adjunct treatment for inflammatory periodontal diseases [17-20].

\section{Catha edulis forsk (Celastraceae)}

Catha edulis is known as Khat, kat or miraa and the leaves and twigs are chewed by several millions of people worldwide for their stimulating amphetamine-like effects [21]. The studies showed that khat is associated with several oral and dental conditions, including keratotic white lesions, mucosal pigmentation, periodontal disease, tooth loss, plasma cell stomatitis, and xerostomia [22, 23]

\section{Citrus Aurantifolia Swing (Rutaceae)}

During dental applications of the polyphenolic compounds of these species have shown that these compounds are improved oral wound healing. Therefore, these polyphenols could be used as a supplemental compounds in mouthwash for periodontal diseases to improve wound healing in the mouth $[24,25]$.

\section{Commiphora myrrha Mr. E. M. Holmes (Burseraceae)}

Commiphora myrrha called as Myrrh is helped promote healing in cases of pyorrhea. Myrrh is also used to eliminate bad breath [26].

\section{Curcuma longa L. (Zingiberaceae)}

Curcuma longa known as Turmeric is to be one of the oldest spices that have been used for thousands of years and is a major part of Ayurvedic medicine. Curcumin, which comprises 0.3-5.4\% of raw turmeric, is its best researched active constituent which is nontoxic and has a variety of therapeutic applications including its usage in dentistry. The extracts of Curcuma longa can be used in the treatment of oral cavity lesions [27, 28].

\section{Gaultheria procumbens L. (Ericaceae)}

Gaultheria procumbens known as Wintergreen is an excellent astringent and antiseptic properties for mouthwashes [29].

\section{Hypericum perforatum L. (Hypericaceae)}

Hypericum perforatum known as St. John's wort, is used in phytotherapy for its well documented antiseptic and antidepressant effects. Moreover, it has been proposed to have antibacterial, antiviral, anti-inflammatory and analgesic activities. Besides, it is a very efficacious antidepressant medication with a potential antioxidant activity [30]. The effect of Hypericum perforatum extract in a rat experimental model of periodontitis was determined for treatment of active inflammatory periodontal diseases. This extract has also exerted a significant inhibitory effect on plasma extravasation and reduced the degree of bone resorption during periodontitis [31].

\section{Lippia sidoides cham. (Verbenaceae)}

The essential oil of Lippia sidoides has exerted promising antimicrobial effects against oral pathogens and suggested its likely usefulness to combat oral microbial growth for the preparation of toothpaste and mouth rinse formulations [32].

\section{Matricaria chamomilla L. (Asteraceae)}

The extract of Matricaria chamomilla was reduced biofilm accumulation and gingival bleeding in patients with gingivitis, probably because of its antimicrobial and anti-inflammatory activities depends on their phenolic compounds particularly apigenin [33-35]. Apigenin inhibits nitric oxide (NO) production and the activities of hyaluronidase, collagenase, and the cyclooxygenases, enzymes that play key roles in the inflammatory process. The anti-inflammatory activity of apigenin was also observed in in vitro studies of human periodontal ligament cells stimulated with nicotine and lipopolysaccharide [36-40]. Although chlorhexidine is used for biofilm control and gingivitis treatment. The clinical studies have showed that the patients receiving 0.12 $\%$ chlorhexidine and $1 \%$ extract of Matricaria chamomilla did not differ for the treatment of gingivitis [41,42].

\section{Melaleuca alternifolia (Maiden \& Betche) Cheel. (Myrtaceae)}

The essential oil of Melaleuca alternifolia called as tea tree oil is used directly on sore, inflamed gum for temporary relief. It is 
also used as mouthwash to soothe oral inflammation. It could hold potential applications in root canal treatment for dissolving the necrotic pulp tissue due to its mild solvent action [43].

\section{Mentha piperita L. (Lamiaceae)}

Peppermint oil is used for the toothaches. Soak a cotton ball in the oil and place it in the cavity or rub it on the tooth. It is also used as mouthwash to relieve gum inflammation [44].

\section{Myrmecodia pendans Merr. \& L.M. (Rubiaceae)}

Myrmecodia pendan known as an "antplant" is used as antimicrobial for the prevention of dental plaque [45].

\section{Pistacia lentiscus L. (Anacardiaceae)}

The resin of Pistacia lentiscus is used in the preparation of dental powder for cleansing of teeth and to remove foul odour of the mouth [46].

\section{Propolis}

Propolis is a plant product collected by honeybees as a resinous mixture from various plants that is mixed with beeswax and other bee secretions. Although the chemical composition of propolis depends on its location of origin, it basically contains beneficial substances, such as phenolic acids, flavonoids, and vitamins. Propolis has been used as a folk medicine depends on its antiinflammatory, antimicrobial and antioxidant properties [47]. On the other hand, propolis suppresses gingivalis-induced metabolic disturbance that increase the risk of various systemic diseases.

\section{Rosmarinus officinalis L. (Lamiaceae)}

Rosemary is used as mouthwash for the treatment of gum disease and bad breath [48].

\section{Salvadora persica L. (Salvadoraceae)}

Salvadora persica known as Meswak tree and the use of Meswak as chewing sticks prepared from the roots and twigs of S. persica is widespread in Middle Eastern, some Asian and African cultures. The utilisation of S. persica for this purpose is particularly prevalent and the resulting meswak has been reported to have beneficial effects on dental health. The relatively strong taste of the meswak extract may have stimulated salivary flow effect. Consequently, meswak inhibits growth and the acid production of Candida albicans. The extract of Salvadora persica is used fort he preparation mouthwashes in improved gingival health and lower carriage rate of cariogenic bacteria [48].

\section{Syzigium aromaticum L. (Myrtaceae)}

Syzigium aromaticum (Eugenia caryophyllata) known as clove is one of the most valuable spices that has been used for centuries as food preservative and for many medicinal purposes. Clove is native of Indonesia but nowadays is cultured in several parts of the world including Brazil in the state of Bahia. This plant represents one of the richest source of phenolic compounds such as eugenol, eugenol acetate and gallic acid and posses great potential for pharmaceutical, cosmetic, food and agricultural applications. The volatile oil of clove buds has been used for a long time in the treatment of minor oral wounds as an analgesic in painful and infective diseases of the oral cavity and oropharynx as well as for general oral hygiene due to the content of eugenol [48].

\section{Terminalia chebula retz. (Combretaceae)}

The properties of various extracts of the fruit of the Terminalia chebula tree have been widely investigated and include antidiabetic, anti-mutagenic, anti-oxidant, anti-bacterial, anti-fungal, and anti-viral effects [49]. The presence of various secondary metabolites including polyphenols, terpenes, anthocyanins, flavonoids, alkaloids, and glycosides [50]. The ethanolic extract of T. chebula was used in preventing periodontal diseases by providing anti-inflammatory effects in gingivitis [51].

\section{Thymus vulgaris L. (Lamiaceae)}

The Mediterranean herb thyme is a source of an essential oil that has been shown to possess antimicrobial activity against many microorganisms. A considerable part of the general population has dental caries and Streptococcus mutans is one of the microorganisms responsible. The $1 \%$ solution of thyme essential oil in ethanol proved to be the most efficient against Streptococcus mutans by using triclosan at $0.25 \%$ and $0.5 \%$, chlorhexidine digluconate at $0.06 \%$ and $0.12 \%$, and ethanol as control. Thyme is used to treat oral herpes and the extract is effective against Streptococcus mutans [32]. It may be considered viable as an ingredient of toothpaste, both with regard to cost and to the sensory profile of the product.

\section{Trifolium pretense L. (Fabaceae)}

Trifolium pretense called as Red clover mouthwash is healing for irritated and diseased gums, It has antibiotic properties, on gums that are abscessed from disease or sore and inflamed from root canal therapy or other dental procedures [39].

\section{Zanthoxylum armatum waterm. (Rutaceae)}

The fruits of Zanthoxylum armatum called as toothache fruit depends on its main use is in toothache. The essential oil of the fruits contain linalool as major constituent [32].

\section{Zingiber officinale L. (Zingiberaceae)}

Zingiber officinale commonly known as Ginger has used for anti-inflammatory and antibacterial properties due to its resin and essential oil in the treatment of dental disorders [32].

\section{Conclusion}

The use of medicinal plants continues to expand in the world for human health care [52]. This review article presents the use of medicinal plants alongwith their extracts for dental disorders. Most of the three major polyphenols (lignin-carbohydrate complex, tannins, flavonoids) containing herbal extracts showed much lower tumor-specificity against oral squamous cell 
carcinoma, in comparison to chemotherapeutic drugs [53-55]. These disappointing observations suggest that the utilization of polyphenols for the therapy of oral cancer is not recommended, despite the numerous publications about the apoptosis induction by lower molecular weight polyphenols. The studies are the basis to discover new, effective and safe preparations for dental use. However, more efficient clinical studies are necessary for further evidence-based evaluation to characterize the active compounds of the herbal extracts as new drug candidates.

\section{References}

1. S Kumar S, Patel J Tadakamadla, H Tibdewal, P Duraiswamy, et al. (2013) Effectiveness of a mouthrinse containing active ingredients in addition to chlorhexidine and triclosan compared with chlorhexidine and triclosan rinses on plaque, gingivitis, supragingival calculus and extrinsic staining. Int. J Dent. Hyg 11(1): 35-40.

2. M Fou, DM lkes (1973) Some toxicological observations on chlorhexidine. J Periodontal Res Suppl12: 55-60.

3. RH Selwitz AI Ismail, NB Pitts (2007) Dental caries. The Lancet 369(9555): 51-59.

4. J Jeon P, Rosalen M Falsetta, H Koo (2011) Natural products in caries reasearch: Current (limited) knowledge, challenges and future perspective. Caries Res 45(3): 243-263.

5. P Kalesinskas, T Kačergius, A Ambrozaitis V, Peciuliene snd D (2014) Ericson, Reducing dental plaque formation and caries development, a review of current methods and implications for novel pharmaceuticals, Stomatol. Baltic Dental and Maxillofac J16(2): 44-52.

6. E Vrani, A La-Evi, A Mehmedagi, A Uzunovi (2004) Formulation ingredients for toothpastes and mouthwashes. Bosnian J Basic Med Sci 4(4): 51-58.

7. AI El-Batal, S F Ahmed (2018) Therapeutic effect of Aloe vera and silver nanoparticles on acid-induced oral ulcer in gamma-irradiated mice. Braz. Oral Res 32: 1-9.

8. AI El-Batal, AF El-Baz, FM Abo Mosalam, AATayel (2013) Gamma irradiation induced silver nanoparticles synthesis by Monascus purpureus. J Chem Pharm Res 5(8): 1-15.

9. LJ Wilkinson, RJ White Chipman, JK Silver (2011) Nanoparticles of silver in wound dressings: A review of efficacy and safety. J Wound Care20(11): 543-549.

10. KJ Kim, WS Sung, SK Moon, JS Choi, JG Kim, et al. (2008) Antifungal effect of silver nanoparticles on dermatophytes. J Microbiol Biotechnol18(8): 1482-1484.

11. A Nasrollahi, K Pourshamsian, P Mansourkiaee (2011) Antifungal activity of silver nanoparticles on some of fungi. Int J Nanodimens 1(3) 233-239.

12. K Chaloupka, Y Malam, AM Seifalian (2010) Nanosilver as a new generation of nanoproduct in biomedical applications. Trends Biotechnol 28(11): 580-588.

13. HH Lara, NV.Ayala-Nuñez, L Ixtepan-Turrent, C Rodriguez-Padilla (2010) Mode of antiviral action of silver nanoparticles against HIV-1. J Nanobiotechnology 28(1):1-10.

14. VF Passos, M A Sampaio de Melo, JP M Lima, F F Marçal, CAGA Costa et al. (2018) Active compounds and derivatives of Camellia sinensis responding to erosive attacks on dentin. Braz Oral Res 32: 1-11.

15. N Jenabian, A A Moghadamnia, E Karami, P B Mir (2012) The effect of Camellia isnensis (green tea) mouthwash on plaque-induced gingivitis: A single-blinded randomized controlled clinical trial. JPharm Sci 20(1): $1-6$.
16. P Kudva, ST Tabasum, NK Shekhawat (2011) Effect of green tea catechin, a local drug delivery system as an adjunct to scaling and root planing in chronic periodontitis patients: A clinicomicrobiological study. J Indian Soc Periodontol15(1): 39-45.

17. Krahwinkle T, Willershausen B (2000) The effect of sugar-free green tea chew candies on the degree of inflammation of the gingival. Eur J Med Res 5(11): 463-467.

18. LE Wolinsky Cuomo, J Qusada, K T Bato, PMA Camargo, T Bato, et al. (2000) comparative pilot study of the effects of a dentrifice containing green tea bioflavonoids, sanguinarine or triclosan on oral bacteria biofilm formation. J Clin Dent 11(2): 53-59.

19. MDR De Moraes, JRM Carneiro, VF Passos, SL Santiago (2016) Effect of green tea as a protective measure against dental erosion in coronary dentine. Braz Oral Res 30: 1-6.

20. M Nakayama, K Suzuki, M Toda, S Okubo, Y Hara,T Shimamura, et al. (1993) Inhibition of the infectivity of influenza virus by tea polyphenols. Antivir Res 21(4): 289-299.

21. SA Al-Maweri, S Warnakulasuriya, A Samran (2018) Khat (Catha edulis) and its oral health effects: An updated Review. J Invest Clin Dent 9(1): 12288-12297.

22. AI Al-Kholani (2010) Influence of Khat chewing on periodontal tissues and oral hygiene status among Yemenis. Dent Res J (Isfahan) 7(1): 1-6.

23. NN Al-Hebshi, N Skaug (2005) Khat (Catha edulis) An updated review. Addict Biol 10(4): 299-307.

24. H C Tsai, YC Li, TH Young, MH Chen (2016) Citrus polyphenol for oral wound healing in oral ulcers and periodontal diseases. JFormosan Med 016Assoc115(2): 100-107.

25. JA Kim, HS Park, SR Kang, KI Park, DH Lee, A Nagappan, et al. (2012) Suppressive effect of flavonoids from Korean Citrus aurantium L. on the expression of inflammatory mediators in L6 skeletal muscle cells, Phytother. Res 26(12): 1904-1912.

26. F Ozaki, CM Pannuti, AV Imbronito, W Pessotti, L Saraiva, et al. (2006) Efficacy of a herbal toothpaste on patients with established gingivitis--a randomized controlled trial. Braz Oral Res 20(2): 172-177.

27. M Shakibaei, A Mobasheri, C Buhrmann (2011) Curcumin synergizes with resveratrol to stimulate the MAPK signaling pathway in human articular chondrocytes in vitro. Genes Nutr 6(2): 1713.

28. MG Correa, PRPires, FV Ribeiro, SZ Pimentel, RCV Casarin, et al. (2017) Systemic treatment with resveratrol and/or curcumin reduces the progression of experimental periodontitis in rats. J Periodont Res 52(2): 201-209.

29. DA Van Strydonck, DE Slot, U Van der, VeldenF, Van der Weijden, et al. (2012) Effect of a chlorhexidine mouthrinse on plaque, gingival inflammation and staining in gingivitis patients: a systematic review. J Clin Periodontol 39(11): 1042-1055.

30. M Menegazzi, R Meli, H Suzuki, S Cuzzocrea (2007) Protective effect of Hypericum perforatum in zymosan-induced multiple organ dysfunction syndrome: relationship to its inhibitory effect on nitric oxide production and its peroxynitrite scavenging activity, Nitric Oxide. 16(1): 118-130.

31. I Paterniti, E Briguglio, E Mazzon, M Galuppo, GOG Cordasco, et al. (2010) Effects of Hypericum perforatum, in a rodent model of periodontitis, BMC Compl. and Alternat. Med 10 (73): 7-10.

32. MA Botelho, NAP Nogueira, GM Bastos, SGC Fonseca, TLG Lemos, et al. (2007) Antimicrobial activity of the essential oil from Lippia sidoides, carvacrol and thymol against oral pathogens. Brazilian J Med Biolog Res 40(3): 349-356.

33. VM Chandrashekhar, VL Ranpariya, S Ganapaty A, Parashar, A A Muchandi, et al. (2010) Neuroprotective activity of Matricaria recutita Linn. against global model of ischemia in rats. J Ethnopharmacol 127(3): 645-651. 
34. VM Chandrashekhar, KS Halagali, RB Nidavani, MH Shalavadi, BS Biradar, et al. (2011) Anti-allergic activity of German chamomile (Matricaria recutita L.) in mast cell mediated allergy model. J Ethnopharmacol 137(1): 336-340.

35. H Sebai, MA Jabri, A Souli, K Rtibi, S Selmi, et al. (2014) Antidiarrheal and antioxidant activities of chamomile (Matricaria recutita L.) decoction extract in rats. J Ethnopharmacol 152(2): 327-332.

36. I Barene, I Daberte, L Zvirgzdina, V Iriste (2003) The complex technology on products of German chamomile. Medicina (Kaunas) 39(2): 127-131.

37. SA Seyyedi, M Sanatkhani, A Pakfetrat, P Olyaee, et al. (2014) The therapeutic effects of chamomilla tincture mouthwash on oral aphthae: a randomized clinical trial. J Clin Exp Dent 6(5): 535-538.

38. EE Mazokopakis, GE Vrentzos, JA Papadakis, DE Babalis, ES Ganotakis, et al. (2005) Wild chamomile (Matricaria recutita L.) mouthwashes in methotrexate-induced oral mucositis. Phytomed 12(1): 25-27.

39. R Pourabbas, A Delazar, MT Chitsaz (2005) The effect of german chamomile mouthwash on dental plaque and gingival inflammation, Iranian. J Pharma Res 2: 105-109.

40. ACL Albuquerque, MSV Pereira, JV Pereira, LF Pereira, DF Silva, et al. (2010) Antiadherent effect of the extract of the Matricaria recutita Linn. on microrganisms of dental biofilm. Rev Odontol UNESP 39: 21-25.

41. M Tolouee, S Alinezhad, R Saberi, A Eslamifar, SJ Zad, et al. (2010) Effect of Matricaria chamomilla L. flower essential oil on the growth and ultrastructure of Aspergillus niger van Tieghem. Int J Food Microbiol 139(3): 127-133.

42. P Goes, CS Dutra, MRP Lisboa, DV Gondim, R Leitão, et al. (2016) Clinical efficacy of a $1 \%$ Matricaria chamomile L. mouthwash and $0.12 \%$ chlorhexidine for gingivitis control in patients undergoing orthodontic treatment with fixed appliances. J Oral Sci 58(4): 569-574.

43. J Gold (2008) The role of chlorhexidine in caries prevention. Oper Dent 33(6): 710-711.

44. H Sakagami (2014) Biological activities and possible dental application of three major groups of polyphenols. J Pharmacol Sci 126(2): 92-106.

45. M Gartika, HT Pramesti, D Kurnia, M H Satari (2018) A terpenoid isolated from sarang semut (Myrmecodia pendans) bulb and its potential for the inhibition and eradication of Streptococcus mutans biofilm, BMC Compl and Alternat. Med 18(151): 1-8.

46. R Chandki, P Banthia, R Banthia (2011) Biofilms: A microbial home. J Indian Soc of Periodontol 15(2): 111-113.

47. M Nakajima, K Arimatsu, T Minagawa, Y Matsuda, K Sato, et al. (2016) Brazilian propolis mitigates impaired glucose and lipid metabolism in experimental periodontitis in mice. BMC Compl. \& Alternat Med 16(1): 329.

48. M Shahzad, E Millhouse, S Culshaw, CA Edwards, et al. (2015) Selected dietary (poly)phenols inhibit periodontal pathogen growth and biofilm formation. Food Funct 6(3): 719-729.

49. DV SuryaPrakash, N Sree Satya, A Sumanjali, V Meena (2012) Pharmacological review on Terminalia chebula. Int J Res Pharmaceut Biomed Sci 3(2): 69-680.

50. R Rathinamoorthy, G Thilagavathi (2014) Terminalia chebula - review on pharmacological and biochemical studies. Int J Pharm Tech Res 6(1): 97-116.

51. J Lee, YH Nho, SK Yun, YS Hwang (2017) Use of ethanol extracts of Terminalia chebula to prevent periodontal disease induced by dental plaque bacteria. BMC Compl and Alternat Med 17(1): 113.

52. I Tomás, MC Cousido, L García-Caballero, S Rubido, J Limeres, et al. (2010) Substantivity of a single chlorhexidine mouthwash on salivary flora: influence of intrinsic and extrinsic factors. J Dent 38(7): 541-546.

53. SS Moghe, S Juma, V Imrhan, P Vijayagopal (2012) Effect of blueberry polyphenols on 3T3-F442A preadipocyte differentiation. J Med Food 15(5): 448-452.

54. H Liu, WJ Xue, YF Xie, XS Feng, FQ Huo, et al. (2011) Tea polyphenolinduced neuron-like differentiation of mouse mesenchymal stem cells. Chin J Physiol 54(2): 111-117.

55. F Giampieri, JM Alvarez-Suarez, L Mazzoni, TY Forbes-Hernandez, M Gasparrini, et al. (2014) Polyphenol-rich strawberry extract protects human dermal fibroblasts against hydrogen peroxide oxidative damage and improves mitochondrial functionality. Molecules19(6): 7798-7816.

\section{ISSN: 2574-1241}

DOI: $10.26717 /$ BJSTR.2019.19.003254

Bilge Şener. Biomed J Sci \& Tech Res

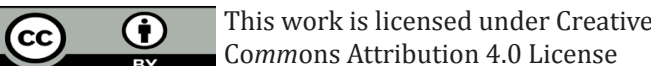

Submission Link: https://biomedres.us/submit-manuscript.php

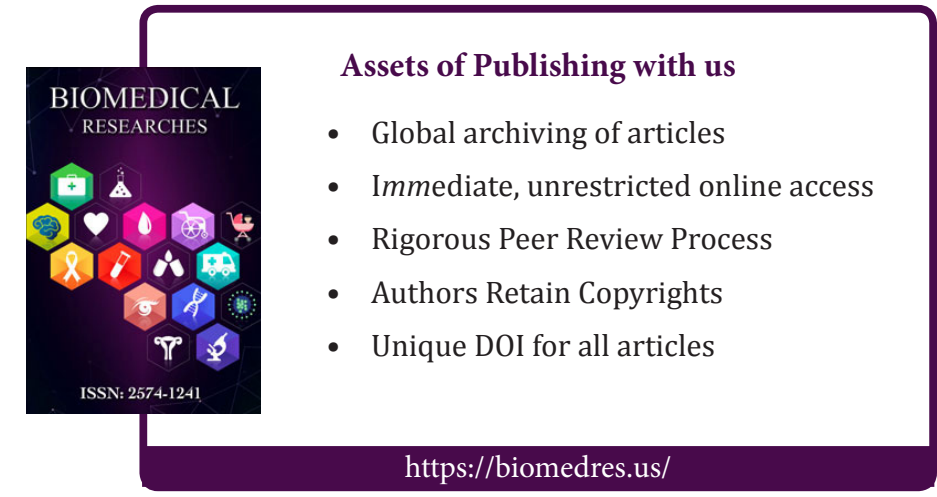

